\title{
Moodle and e-learning Tools
}

\author{
Zahraa F. Muhsen \\ Department of computer sciences, Isra University, Amman, Jordan \\ Email: z_muhsin@ipu.edu.jo \\ Adi Maaita \\ Department of computer sciences, Isra University, Amman, Jordan \\ Ashraf Odah \\ Department of computer sciences, Isra University, Amman, Jordan \\ Email: ashraf.odeh@ipu.edu.jo, \\ Ayman Nsour \\ Department of computer sciences, Isra University, Amman, Jordan
}

\begin{abstract}
Online interactions provide a large knowledge exchange on variety kinds of information exchanged between users. There are many software systems available that provide online learning systems, this type of software expressed by forms, commercial or open source software. This paper is focused on Moodle, it explained the comparative study that done by many recent researches, it also shows the different between Moodle and other learning management systems, in order to discover their strengths and limitations, discusses different points in these systems. Moodle has been adopted by many universities and organizations the entire world because it offers a large accusable set of tools, and many components was developed without a specific design documentation including its security services. This paper shows the comparative study between Moodle and other e-learning systems; it aimed to discover the best and most suitable choice of elearning system. We have fined the optimal e-learning platform required to our e-learning university system, and it is Moodle, according to the used by many Universities around the word and from many works that has been done to date that encourages the used and develops this type of LMS.
\end{abstract}

Index Terms - Moodle, Learning Management System, E-learning, Course Management System.

\section{INTRODUCTION}

E-learning is the technology based learning, which becomes an important part of the strategy for delivering an online and flexible learning. The main advantage of e-learning is the opportunity to interact electronically. There are more than 250 commercial e-learning system and more than 45 free Open Source Software (OSS). Elearning may cover a large set of application, system and process, such as e-learning system, web based learning, blended learning, visual class learning, and computer based learning. In 2006, hundreds of e-learning systems were introduced, major milestone happened in 1997 when WebCT 1.0 and Blackboard was released and attracted millions of users. The Modular ObjectOriented Dynamic Learning Environment (Moodle) has been introduced as a Learning Management Systems (LMS), in 1998 and released in 2001.Moodle It becomes the most common used LMS at that time.. Moodle has the ability of tracking the learner's progress, and can be monitored by both teachers and learners. This fact implicitly includes both security and privacy threats and makes Moodle vulnerable system.

The most known OSS are Moodle, Ilias, eduplone, Claroline, SAKAI, WebCT and Bscw. All the above OSSs have wide developer communities who present robust arguments for considering them as a straightforward and potentially feasible competitor to commercial products. One of the OSS projects that have emerged to meet the growing interest in the OSS is the Moodle [1-5].

Moodle is also known as a Course Management System (CMS), LMS, Virtual Learning comparison Environment (VLE), and OSS e-learning platform which provides educators tools to create a course web site. It is used in 193 countries, with 400,000 registered users. Moodle web page provides developer information, roadmap, coding guide and concurrent versioning system guide to access its source code and it has a long list of developers. It does not provide a formal model for future development [6]. Moodle is a medium-scale application, totaling 625473 LOC across 2331 PHP files. The Moodle website reports a total of 39412496 users across 211 countries [7, 8].

This paper is structured as follows. Section II shows the general variation in the configuration of e-learning system, the way to manage the site of the Moodle is presented in Section III, containing the reasons for choosing Moodle together with its limitations. The comparative study between Moodle and other LMSs are described in Section IV. Section V talks about the upgrade and requirement to Moodle 2.x. Section VI shows the MOOCH site and discussed its features. Finally a brief conclusion is described in Section VII. 


\section{E-LEARNING CONFIGURATION}

The variations in the configuration of many LMS offerings can be described through a number of attributes, decried in Figure 1. Many university courses contain several components, each with different attribute values. The components of any success course should be delivered synchronously and others asynchronously, that mean it should involve some online components and some in-class components. Most of the courses available on the Internet are based on this asynchronous model. Also the location of study may be learning at same time includes technology (video conferencing and electronic white boards), or at different time learning applications (programmed instruction and tutorials that allow students to work through the screens at their own pace and at their own time). Students can be involved in e-learning from distributed locations, such as using a group support system in a classroom to work on an assignment. Courses applications also differ in the levels of collaboration, some courses are entirely independent and individual, while others groups need discussion forums or chat rooms. The mode of course delivery can be with or without an instructor or take a more blended approach integrating electronic and classroom delivery to varying extents. Many current LMS are taking the advantage of the benefits of various types of delivery [1, 9].

\section{MOODLE SITE}

When the site of the Moodle installed, the administrator will be in charge of it, although some tasks may be delegated to others by assigning them a role such as Manager. Table (1) provides the main information about how to manage the Moodle site [10]. Table (1) shows Authentication: which allow the user login and other addition that related to the user regestration. Managing accounts: this process allow user to perform action such as edit or delete and other activeties. Enrolments: a methods for adding student to the course in the e-learning system. Roles \& Permissions: these tasks are necessary for desiging and controlling student/teachers permissions. Security: different security wayes required for the e-learning system. And other manages such as: Performance, Backup, Site appearance, Language, Registration, Site wide reports, Developer tools, Web services, Community hubs.

\begin{tabular}{|c|c|}
\hline \multirow{2}{*}{ Synchronicity } & Lecture asynchronous deliver at different time (e. g. email) \\
\hline & Lecture synchronous deliver at same time (e. g. web cast) \\
\hline \multirow{2}{*}{ Location } & Student use an application at same place (e. g GSS in classroom) \\
\hline & Students use an application at various paces (e. g. GSS in distributed locations \\
\hline \multirow{2}{*}{ Independence } & Student work independently from one another (autonomously) \\
\hline & Students work collaboratively with one another (share ideas) \\
\hline \multirow{2}{*}{ Mode } & An electronically enabled distance learning course \\
\hline & In class lectures are enhanced with handson computer exercises \\
\hline
\end{tabular}

Figure 1. The Dimensions of E-Learning [9] 
TABLE I. The Important Points for Designing The MoOdLE Site

\begin{tabular}{|l|l|}
\hline \multicolumn{1}{|c|}{ Process } & \\
\hline Authentication & The process of allowing a user to login, different methods of adding new users. \\
\hline Managing accounts & Search for, edit, delete or perform bulk actions on users. \\
\hline Enrolments & $\begin{array}{l}\text { Different methods of adding users. It is the process of assigning users to roles } \\
\text { (usually student) in a course. }\end{array}$ \\
\hline Roles \&Permissions & Add or remove permissions from students, teachers and other users on. \\
\hline Security & There are many ways to customize the appearance of the site so that it blends in \\
\hline Performance & with. \\
\hline Backup & Check the efficiency and smooth running of the site. \\
\hline Site appearance & How to backup your site and courses. \\
\hline Language & Change the display and navigation of site. \\
\hline Server settings & Add new languages and alter the default terms used. \\
\hline Site wide reports & Registration, maintenance and default settings. \\
\hline Developer tools & A list of useful reports for administrators. \\
\hline Web services & Debug your site, purge caches and tools for test sites only. \\
\hline Community hubs & Connect other systems to Moodle to perform operations. \\
\hline Blogs, Comments, Tags, Messaging, Notes, RSS feeds, Calendar, are more features required to manage the site. \\
\hline
\end{tabular}

\section{COMPARATIVE OF MOODLE WITH OTHER E- LEARNING SYSTEM}

Moodle has a good architecture, implementation, inter-operability, and internationalization, and also has the strength of the community. It is free and its accessibility is average. On the other hand, it has limitations, notably lack of SCORM support, and its roles and permissions system is limited. However, these limitations can be fixed, and are part of the project roadmap [3, 4].

\section{A. Features and Capabilities}

Ajlan and Zedan [2] have shown a simpler and simplify comparison study using three features tools: Learner Tools, Support Tools and Technical Tools. Learner tool contains various features and capabilities, four products are shown to be the best with almost the maximum number of features, 15/16 features of learner tools. These products are Moodle, Desire2Learn, ANGEL learning management suite, and Sakai. The Claroline 1.6 product has the minimum features of learner tools, missing 5/16 features. KEWL, eCollege and the Blackboard learning system platforms have missed 2/16 feature. Moodle is the best with three products missing 1/16 features. Overall the best OSSs are Moodle and Sakai respectively, which missed 1/16 features of learner tools. The support tools show many LMSs products which have all features except eCollege, Dokeos 2.1.1 and Blackboard learning system (V.7). The costs feature is different from other tools since there is no cost on the software that will be a good point. At the end score Moodle has missed just one feature than other LMS. Moodle (1.8) and other LMS in technical specifications tools, have missed $1 / 8$ features. But Desire2Learn 8.1, Blackboard learning system and Dokeos 2.1.1, have missed 2/8 features. The weakest products are KEWL and Claroline 1.6, which missed 4/8 features $[3,4,11]$.

\section{B. Communication Tools}

Maneva and Tauchmanova in [13] have shown the results of the study done in University of Hradec Kralove that compared two LMSs (Moodle a WebCTBlackboard), since the academic year 2011/12, these two systems have been researched from various, points of view, that done on the comparison of the Moodle with the WebCTBlackboard system, and in their study they constrained at the communication tools and the possibilities of their use by student the evaluation process done by the student in the survey shows that the tool of Discussion Forum in Moodle higher than the WebCT- Blackboard system but the E-mail tool supported by the Moodle has less recourse than the blackboard system, From he results of the Chat tool it is 
clear that the Moodle environment has a similarly evaluation result as the other learning environment. The statistical significance of the difference in the evaluationswas not confirmed [14].

\section{Collaboration Tools}

Three studies [14-16] showed that students preferred Moodle because it was easy to use and had rich communication and collaboration tools. From developers' prospective, Moodle had more tools for the learning environment, and it is easy to incorporate multimedia elements and has a desired features. From the instructors' views, different users had different preferences, mainly from their experience and knowledge of LMS. There is no doubt that Moodle has some advantages over other LMSs. according to the Mitchell et al. report (2005). Wainwright et al. (2007) study showed while four different colleges with similar size and needs have chosen a different LMS to support and maintain their online teaching and learning, the tools that the LMSs offer are very similar. The campus culture had a big influence on the decision making. Many colleges chose Moodle because of its strong community based structure; Machado and Tao in [13] believe an OSS gives users the freedom to develop the system they require and the ability to integrate existing products [16].

\section{UPGRADING TO MOODLE 2.X}

Moodle website [17] release many document to encourage university to work with Moodle 2.x. Universities started to upgrade their Moodle platform with Moodle 2.x (2.0, 2.1, 2.2, 2.3 or 2.4). These versions required many planning and testing then the old one (1.9 and later). Moodle 2.0 platform does not accepted to be straightforward as upgrades through earlier versions; it is different to the moodle 1.9 versions.

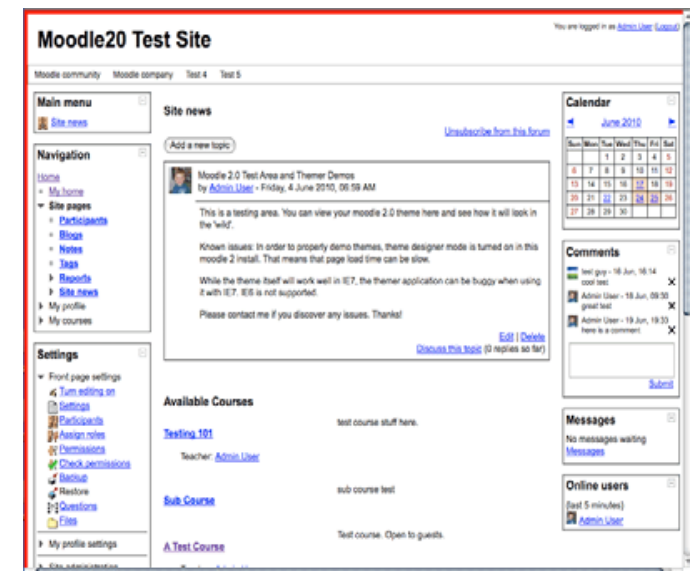

Figure 2 shows an example test view for moodle 2.0.

Figure 2. Moodle 2.0 Test Web site layout design

Table 2 shows the requirements tools to install Moodle 2.0. The Moodle 2.x show some changes in the user interface of the old Moodle interface layout. Moodle site pointed that "if something goes wrong you cannot go back, the upgrade process will irreversibly modify the contents of your database and your moodle data file storage area). The major new and improvements features that have been release by Moodle.org [17,18, 21,22, 23] are summarized as follow:

New features: community hubs (Figure 3), repository support, portfolio support, course completion and prerequisites, conditional activities, cohorts, web services support, new blocks, plagiarism prevention, repository integration, proftfolio integration, conditional actives, course completion, progress tracking, feedback module, bolg 2.0, resources 2.0, sit-wide groups, web services API, IMS CC, totally flexible user fields

Improvements existing features: backup and restore, blocks, blogs, comments, enrolment plugins, file handling, filters 2.0, HTML editor, messaging, my Moodle page, navigation, ratings, roles and permissions, secure RSS feeds, themes, translation system, user profile pages.

Improvements activity modules: lesson 2.0, quiz module and question bank, resource, SCORM, Wiki 2.0, workshop 2.0, javascript handling, database access/ data handling, File storage and handling, roles and enrolments, messaging, backups, gradebook and roles, navigation and blocks, themes, text formats, commenting.

M. Dougiamas [19] write about the new features that releases at Moodle 2.3 in changes of course layout features which have a new section-per-page feature, the AJAX for managing the course has been cleaned up, new "add activity or resource" - the activity chooser, drag and drop of files directly to the course page which developed by Davo Smith, new quick-edit, and the ability to add/remove sections using a plus and minus icon. Other features for the changes in 2.3 came out by a survey that Moodle HQ ran in December such as changes to the File picker. A new file manager has the new drag and drop which is a nice visual friendly manager that has auto-generated thumbnails for images. The default icon driven view, a table view and a tree view so it is much easier to navigate back through courses in server files. There is also a nice sort by last modified, size and type which is very handy!

M. Dougiamas [20] indicate that Moodle 2.4 has release the following features: adding a new cool caching system, course formats are more flexible and pluggable, new course/category management interface, a new icon set and graphic design, increased in usability, a repository plugin for direct audio/video recording, a look at reviewing forum and Wiki, importing of iCal streams to make calendar synching much easier.

According to M. Dougiamas and the Moodle.org site, there are number of new features that increased ease-ofuse and enhanced usability in general at the new Moodel 2.x. The most main features are in the new question engine, restoring of Moodle 1.9 backups is now possible, Mobile Apps, file preview information, re-use a file in multiple places, file information, EQUELLA integration demoed, Netspot reworked Assignment module. The old assignment types become a 3rd party module in Moodle 2.4 probably. The marking guide, is similar to rubrics 
which is a list rather than a scale. Book module, workshop module and quiz module have had some improvements. A new SCORM graph report has been created. They also improved the automatic phase switching, submission deadlines show in calendar, plugin updates , and pagination support and filtering.

TABLE II. MOODLE 2.0 REGUIREMENTS

\begin{tabular}{|c|c|}
\hline Requirement & Description \\
\hline System & $\begin{array}{l}\text { - programing language: PHP must be } 5.2 .8 \text { or latest 5.3.x. } \\
\text { - Databases: MySQL 5.0.25, PostgreSQL 8.3, Oracle 10.2, MS SQL } 2005 \text { or any later } \\
\text { versions. } \\
\text { - Standards-Supporting Browser: Firefox 3,Safari 3,Google Chrome 4, Opera 9, MS } \\
\text { Internet Explorer } 7 \text { or any later versions. }\end{array}$ \\
\hline $\begin{array}{l}\text { Operating } \\
\text { Systems }\end{array}$ & $\begin{array}{l}\text { - Required a full database backup and moodledata backup. } \\
\text { - if you are using any PHP accelerator then purge PHP cache }\end{array}$ \\
\hline $\begin{array}{l}\text { Database } \\
\text { Privileges }\end{array}$ & $\begin{array}{l}\text { Database account defined in config.php is allowed to create temporary tables. For } \\
\text { MySQL is controlled by CREATE TEMPORARY TABLES privilege. }\end{array}$ \\
\hline
\end{tabular}

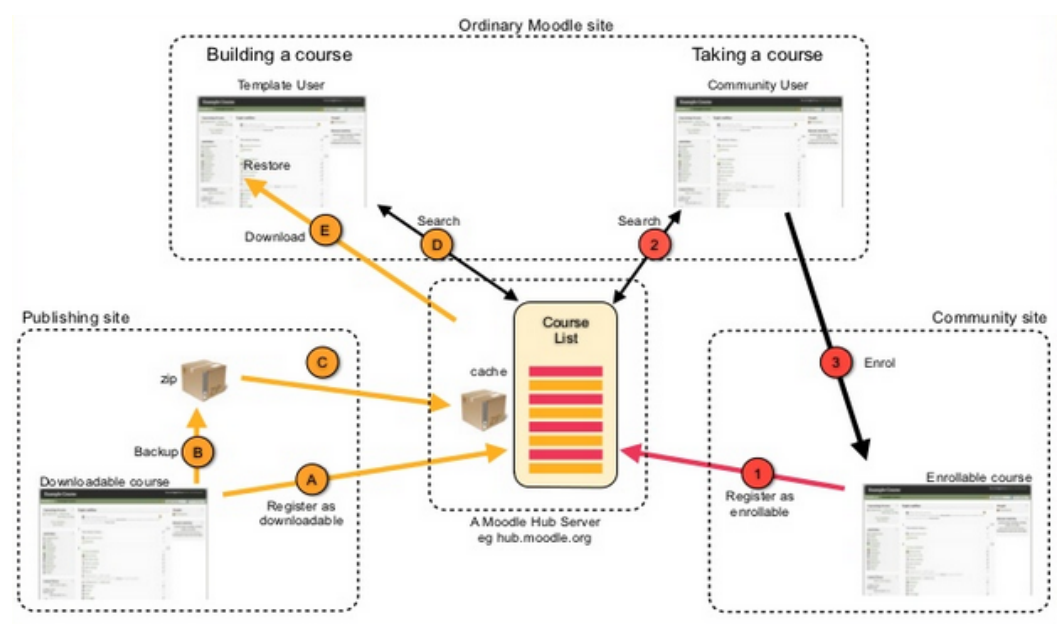

Figure3. Community hubs as shown in [21] the diagram are (Ordinary Moodle site: A typical Moodle site with teachers who want to download course templates and/or users who want to connect (enrol) with external communities, Publishing site: A Moodle site: that wants to make some of its courses available for download, Community site: A Moodle site that provides courses that are enrollable).

\section{MOOCH}

Moodle.org create a share directory for Moodle 2.0 courses site for Moodle users that is called Moodle.org Open Community Hub (MOOCH) (Figure 4). MOOCH is the hub feature that connects Moodle 2.0 installations using the Community hub feature. Courses in $\mathrm{MOOCH}$ are available (for free/paid) for searching to download or enrol in, they also could monitor newly published courses via RSS or follow @moodlemooch on Twitter. Course at MOOCH need to be approved by the hub administrator before it appears in the course listing, $\mathrm{MOOCH}$ allows courses to be update at any time. Email-based self- registration enabled for the site and enabling self enrolment for the course. [24, 25,26, 27, 28].

Courses must satisfy certain criteria in order to be approved and published for sharing on MOOCH. Sites, they must first be registered with hub servers (either go to hub.moodle.org, or ensure your Moodle site is registered with $\mathrm{MOOCH}$ ). Then hub administrator will check both course content and manage a course security process. The download process may trigger the backup process on the original server. Later, Moodle users (who have permissions) can connect to a hub to search for down loadable courses and choose one. The Moodle site downloads the file and makes it available to the Moodle user. Later, any Moodle user can connect to a hub (via 
Community block in their site) to search and find courses they want to join[24, 25].

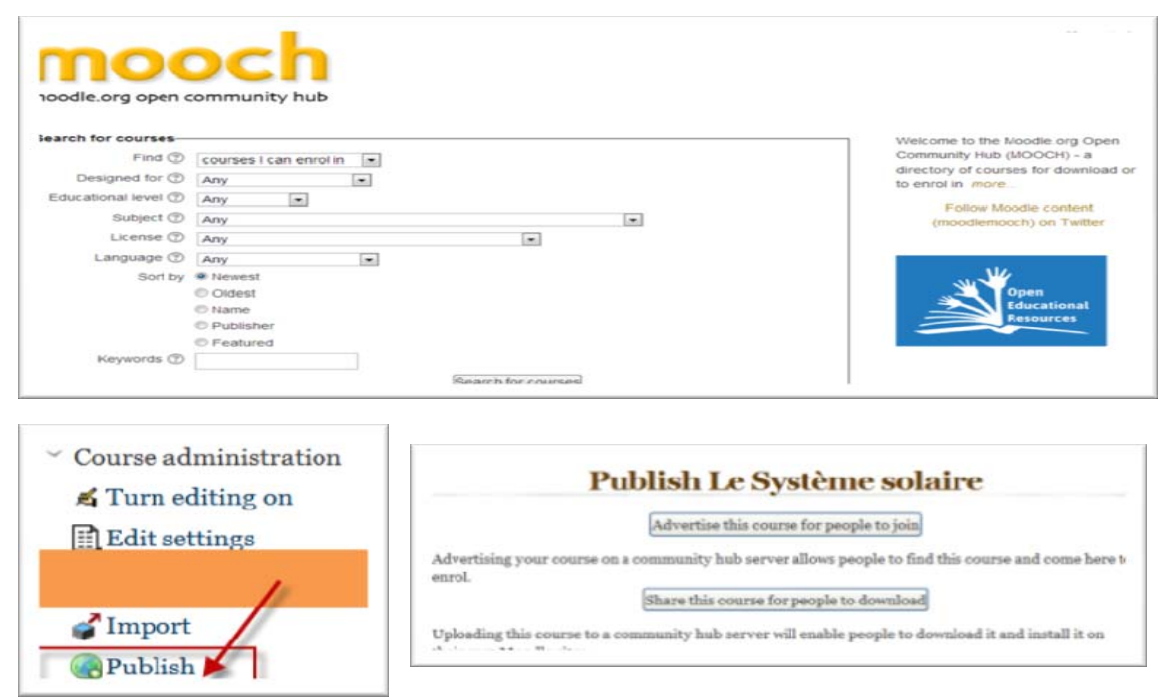

Figure 4. Moodle.org Open Community Hub (MOOCH), shows the steps for Connecting to a community hub. Managers that capabily for publish a courses at MOOCH can publish courses as shown in Figure 3.b and 3.c. [24, 25]

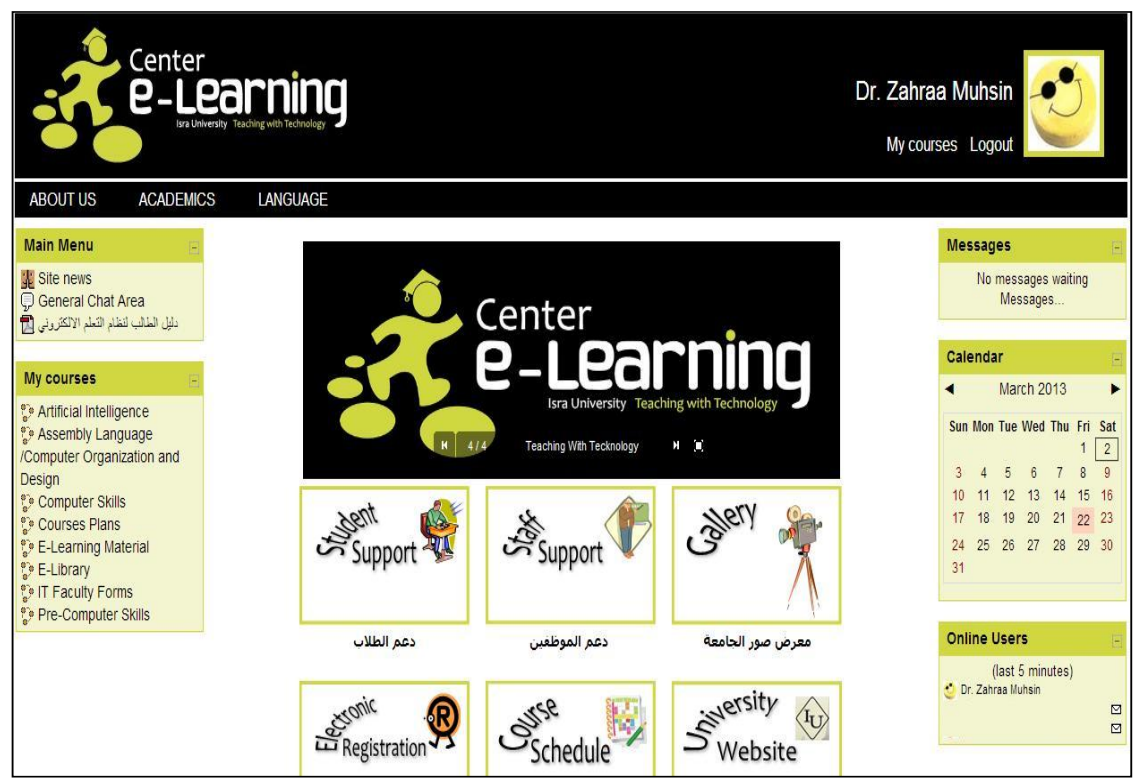

Figure 5. IUELS design and manage by IUELC main page lyout.

\section{MOODLE IN ISRA UNIVERSITY}

Many faculty member at Isra university (IU) write articals about the important and the features of using Moodle as an e-learning system at IU. IU create a elearning center called IUe-learning center (IUELC) that mange and update the e-learn system Moodle . Most courses submited to IUELC and all student at IU are enrolled too. The courses are aranged in IU Moodle, and many activite have been enably to access. The IUELC enrolled other not study courses (services courses), such as e-library, courses plan, university forms, and other usefl courses for faculty used. The IUELC allowed to brows other university site throw the
IUELS such as: student support, staff support, gallery, electronic registrations, course schedule, university web site. Figure 5 shows the IUELS designed which managed by IUELC.

\section{CONCLUSION}

The success of the e-learning paradigm observed in recent times created a growing demand for e-learning systems in universities and other educational institutions, that itself led to the development of a number of either commercial or open source LMS, also the success of implementing any e-learning system is dependent on the needs and concerns of the organization groups that used 
the system, and this will led to encourage the e-learning in higher education.

Moodle is a kind of e-learning system that been used in many Jordan Universities, and it is widely used all over the world by companies, independent educators, schools, institutes, universities, and home schooling parents. It has great potential for creating a successful elearning experience by providing an abundance of excellent tools that can be used to enhance conventional classroom instruction in any e-learning system. This paper has made a comparative study between Moodle and other e-learning systems; we aimed to discover the best and most suitable choice of e-learning system. We have succeeded in finding that optimal e-learning platform, and it is Moodle according to the used by many Universities and from many works that has been done to date that encourages the used and develops this LMS. The comparison was realized in the blended learning environment of the selected subject. The attention was focused on the many tools of the LMSs concerned. The development and maintenance of the OSS would greatly depend on the capabilities of the IT team within the university. However, the more development on the OSS codes, the more support required for maintenance and upgrade.

\section{REFERENCES}

[1] Z., Stapi, T. Orehovaki, M. ani, Determination of Optimal Security Settings for LMS Moodle, in: Proceedings of 31st MIPRO International Convention on Information Systems Security, Vol. 5, Opatija, 2008, pp. 84.-89.

[2] A. Al-Ajlan, H. Zedan, Why Moodle, in: 12th IEEE International Workshop on Future Trends of Distributed Computing Systems, 2008, pp. 58-64.

[3] M. Dougiamas, Moodle, Available from: http://www.Moodle.org, 2008.

[4] EduTools., Course Management Systems. 2007 Available from: http://www.edutools.info/.

[5] J. Massy, Study of the e-learning suppliers "market" in Europe. 2004, Final Report, HeriotWattUniversity.

[6] M. Berry, An investigation of the effectiveness of Moodle in primary education, in Deputy Head. 2005, Haslemere.

[7] Moodle statistics, January2011, Available from: http://moodle.org/stats/.

[8] Gauthier, F.; Letarte, D.; Lavoie, T.; Merlo, E., Extraction and comprehension of moodle's access control model: A case study", Privacy, Security and Trust (PST), 2011 Ninth Annual International Conference on Montreal, 19 July 2011, pp. 44 - 51. DOI:10.1109/PST.2011.5971962.

[9] Wagner, N., Hassanein, K., \& Head, M. Who is responsible for E-Learning Success in Higher Education? A Stakeholders' Analysis in Educational Technology \& Society, 11 (3), 26-36, 2008.

[10] Main Page, Available from: http://docs.moodle.org/20/en/Main_page.
[11] M. Zenha-Rela and R. Carvalho, Work in Progress: Self Evaluation Through Monitored Peer Review Using the Moodle Platform," in Frontiers in Education Conference, 36th Annual, San Diego, CA: IEEE, 2006, 230-241. DOI:10.1109/FIE.2006.322458.

[12]Kumar,S. A.; Gankotiya,K. and Dutta,K., A comparative study of moodle with other e-learning systems', Electronics Computer Technology (ICECT), 3rd International Conference on, Kanyakumari, April , 414 - 418, 2011. DOI:10.1109/ICECTECH.2011.5942032.

[13] M.Manenova,and V.Tauchmanova , Analysis of Communication Tools of the Learning Management Systems of Moodle and WebCt" 10th WSEAS International Conference on Education and Educational Technology (EDU '11) , Malaysia , October 3-5, 2011, pp. 82-86.

[14]Bremer, D., \& Bryant, R. A Comparison of Two Learning management Systems: Moodle vs. Blackboard (pp. 135-140). Concise paper. Otago Polytechnic. Dunedin, NZ. 2005.

[15] Machado, M. \& Tao, E., Blackboard vs. Moodle: Comparing user experience of Learning Management Systems, Proceedings of the 37th ASEE/IEEE Frontiers inEducation Conference (pp. S4J-7 - S4J-12). IEEE. Retrieved March 23, 2009. DOI:10.1109/FIE.2007.4417910.

[16]Li, Y., A Comparison of Learning Management Systems", 22nd Annual NACCQ, conference proceeding 2009, pp.157.

[17] Main site for Moodle available from http://www.Moodle.org.

[18] Moodle_2.0_release_notes , Available from http://docs.moodle.org/dev/Moodle_2.0_release_not es.

[19] M.Dougiamas, Moodle 2.x, 2012, Available from http://www.synergy-learning.com/blog/tag/martindougiamas/.

[20] M. Dougiamas , Moodle 2.3 features “, Keynote from at iMoot 2012, Available from http://docs.moodle.org/dev/Moodle_2.3_release_not es.

[21]M. Dougiamas , Moodle 2.0 Overview',2010, Available from http://www.slideshare.net/moodler/moodle-2overview.

[22] J. Milne, Web 2.0 and the legal implications from JISC Legal", Keynote speaker at Integration Learning Together 2009 JISC RSC, Regional Support Centre Wales, available from: http://moodle.rsc-wales.ac.uk/mod/book/view.php? id=3401\&chapterid=280.

[23] J. Cole, G. Henrick, J. Cole, Moodle 2.0 for Business Beginner's Guide, published by Packt Publishing BIRMINGHAM, MUMBAI, 2011.

[24] $\mathrm{MOOCH}$ main site available from http://hub.moodle.org/?sesskey=jmQlcaXaXY\&_qf _course_search_form $=1 \&$ downloadable $=1 \&$ audie nce $=$ educators\&educationallevel=primary\&subject $=$ 
field1100705\&licence $=$ public\&language $=$ ar\&order by=newest\&search=\&submitbutton=Search + for + co urses.

[25] MOOCH FAQ available from: http://docs.moodle.org/23/en/MOOCH_FAQ.

[26] Check out new courses at the MOOCH, Available from http://www.moodlenews.com/2011/check-outnew-courses-at-the-mooch/.

[27] Stay up to date on published courses from the Mooch with RSS, available from; http://www.moodlenews.com/2011/stay-up-to-dateon-published-courses-from-the-mooch-with-rss/.

[28] Moodle 2.0 Preview Release 4 and Introducing the "MOOCH" (course hub), available from: http://www.moodlenews.com/2010/moodle-2-0preview-release-4-and-introducing-the-moochcourse-hub/.

Dr. Zahraa Fadhil Muhsen is an assistant profesor at Isra university since 2005 until now, work in department of computer siencse.

Dr Adi Maaita is an assistant profesor at Isra university since 2008 until now, work in department of software engineering.

Dr. Ashraf Odah is an assistant profesor at Isra university since 2010 until now, in department of computer siencse.

Dr Ayman Nsour is a professor at Isra University , in the departement of computer science. 